\title{
Is the food provided in nursery schools in England adequate to meet the nutritional needs of children under five years old?
}

\author{
E. L. Thorn and B. A. Griffin \\ Faculty of Health \& Medical Sciences, University of Surrey, Guildford, Surrey GU2 7XH, UK
}

Despite evidence to show that the diet of pre-school children is high in non-milk extrinsic sugars (NMEs) and sodium, and low in vitamins (A, C, D), zinc, iron and fibre ${ }^{(1)}$, there are currently no nutrient-based or food-based standards in nursery schools in the UK. National statistics show that almost 1 in $4(23.1 \%)$ of children starting reception school (age 4-5 years old) are obese or overweight ${ }^{(2)}$. While nutritional guidelines for primary and secondary state schools are set in place ${ }^{(3)}$, evidence suggests that intervention during early years may provide the most effective means of preventing chronic diseases in later life ${ }^{(4)}$. The primary aim of this study was to assess whether the food provided in nursery schools in England meets the nutritional needs of 1-4 year old children. This study compared menus from five nursery schools in different social-economic areas against the Caroline Walker Trust (CWT) nutrient-based standards for children aged 1-4 years ${ }^{(5)}$. Ingredients, recipes and average daily menus over a 4 week menu cycle, were collated from each nursery school, analysed using the nutritional analysis software, 'Relish' ${ }^{(6)}$, and compared against the CWT nutritional standards.

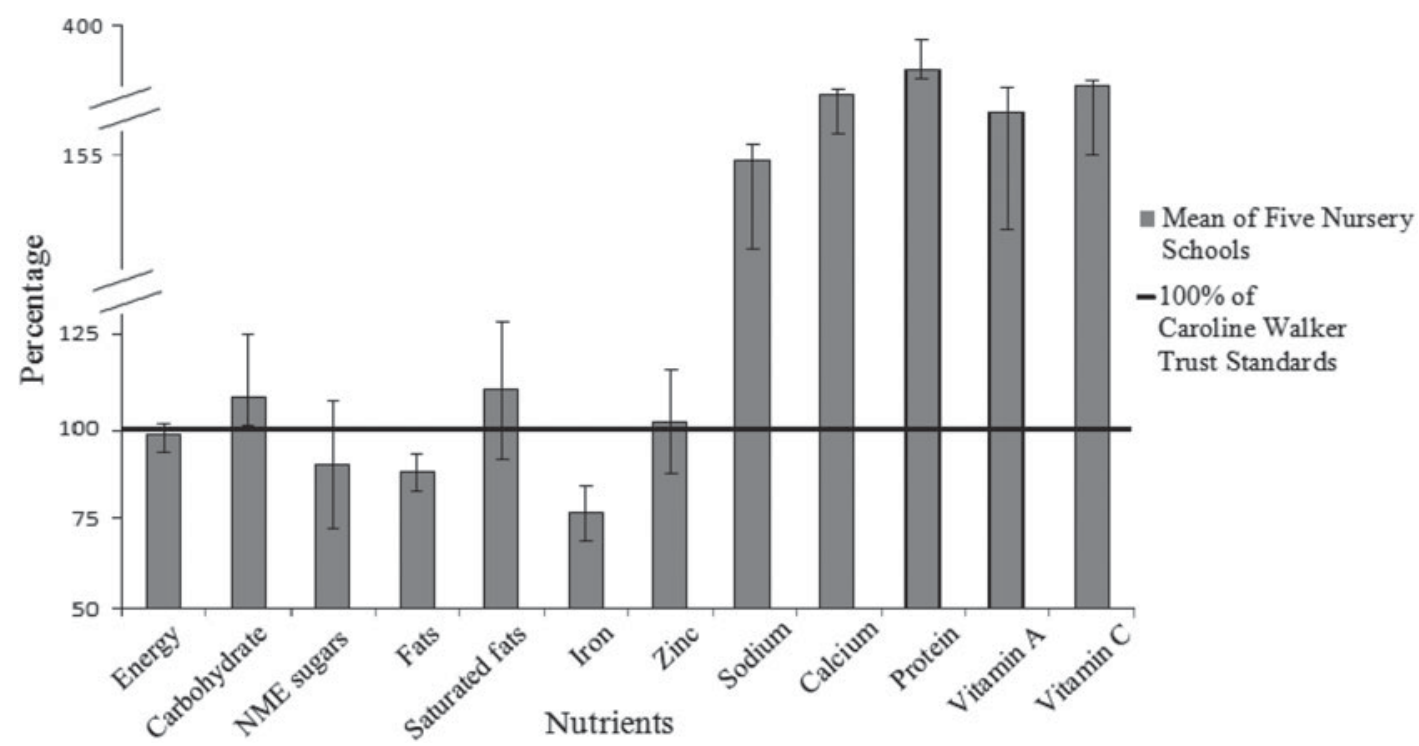

The Figure shows the mean percentage of CWT standards met by the menus at the five nursery schools. All of the nursery menus were providing insufficient iron and an excess of sodium; ranging from menus with 140-166\% of the sodium standard and 64-82\% of the minimum iron standard. In contrast to previous findings, NME sugars were below the $100 \%$ CWT standard. None of the nursery schools met all of the final food-based standards set in place in primary and secondary state schools. Many served confectionary, crisps, large amounts of meat products and fried foods, and no oily fish. In particular, the high sodium content in the menus indicates a need for a restriction on salty foods (meat products and crisps). In conclusion, as the number of children in childcare is rising ${ }^{(7)}$, there is a pressing need for nutrient-based and food-based standards to be established in nursery schools to ensure that the nutritional needs of $1-4$ year old children are met.

1. National Diet and Nutrition Survey: children aged $1^{1 / 2}$ to $4^{1 / 2}$ years. Volume 1 (1995) HMSO

2. The Health \& Social Care Information Centre, Lifestyle Statistics (2009/10) school year 7-8.

3. School Food Trust (2009); www.schoolfoodtrust.org.uk/the-standards.

4. World Health Organization (2003). WHO Technical Report Series no. 916. Geneva: WHO.

5. Caroline Walker Trust. (2005) Practical and Nutritional Guidelines 65-66.

6. Pelican Buying Company. (2011) Relish, Nutritional Analysis Tool powered by Nutriplanner.

7. School Food Trust. (2010) Preliminary Review of Early Years Food. A Summary, 5-6. 